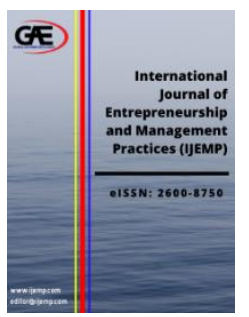

\author{
INTERNATIONAL JOURNAL OF \\ ENTREPRENEURSHIP AND \\ MANAGEMENT PRACTICES \\ (IJEMP) \\ www.ijemp.com
}

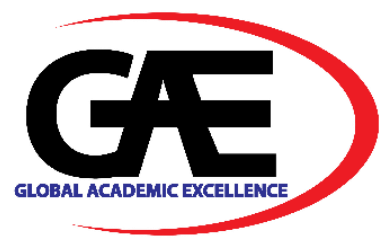

\title{
SUSTAINABLE FINANCIAL DEVELOPMENT FOR SMALL MEDIUM COFFEE FARMERS IN SUMEDANG REGENCY, INDONESIA
}

Raden Aswin Rahadi ${ }^{*}$, Yunieta Anny Nainggolan ${ }^{2}$, Kurnia Fajar Afgani $^{3}$, Ima Mulyama Zainuddin ${ }^{4}$, Mia Rosmiati ${ }^{5}$, Aisyah Moulyni ${ }^{6}$, Ainindita $^{7}$

$1 \quad$ School of Business and Management, Institut Teknologi Bandung

Email: aswin.rahadi@sbm-itb.ac.id

2 School of Business and Management, Institut Teknologi Bandung

Email: yunieta@sbm-itb.ac.id

3 School of Business and Management, Institut Teknologi Bandung

Email: kurnia.fajar@sbm-itb.ac.id

4 School of Life Sciences and Technology, Institut Teknologi Bandung

Email: ima.mulyama@gmail.com

5 School of Life Sciences and Technology, Institut Teknologi Bandung

Email: mia@sith.itb.ac.id

6 School of Business and Management, Institut Teknologi Bandung

Email: aisyah_moulyni@sbm-itb.ac.id

7 School of Business and Management, Institut Teknologi Bandung

Email: ainindita@sbm-itb.ac.id

Corresponding Author

\section{Article Info:}

Article history:

Received date: 05.04.2021

Revised date: 26.04 .2021

Accepted date: 21.06 .2021

Published date: 30.06 .2021

\section{To cite this document:}

Rahadi, R. A., Nainggolan, Y. A., Afgani, K. F., Zainuddin, I. M., Rosmiati, M., Moulyni, A., Ainindita. (2021). Sustainable Financial Development For Small Medium Coffee Farmers In Sumedang Regency, Indonesia. International

\section{Abstract:}

Coffee is one of Indonesia's leading export commodities. One of the coffeeproducing areas in Indonesia is Sukawangi Village, Sumedang Regency, West Java Province. As the sole actor in running a business, the business actor never calculates the production costs that arise into the cost element. One of the problems of SMEs is the lack of knowledge of SME entrepreneurs about good business management. The next problem faced by SME entrepreneurs is increasing their business competitiveness. Another problem of SMEs that often escapes the attention of UKM entrepreneurs is branding. The last mistake that many UKM players make is that many are not aware that manual bookkeeping is a serious problem for SMEs. In this study, the authors performed a literature synthesis to understand the underlying reasons for issues faced by SMEs about good business management. From the analysis, it can be concluded that consumer behaviour/ preferences/ shops; value chain/ geographical; sustainability/ environment; finance farming; regulation/ certification; and COVID-19 plays a significant part in determining the success of coffee 
Volume 4 Issue 14 (June 2021) PP. 01-12

DOI: 10.35631/IJEMP.414001

Journal of Entrepreneurship and production. Further studies should be performed to test this conceptual model Management Practices, 4 (14), 01-12.

DOI: $10.35631 /$ IJEMP.414001.

This work is licensed under CC BY 4.0 in Indonesia. The results of the study can be useful for all the stakeholders in the coffee Industry, particularly the coffee farmers.

Keywords:

Coffee, Sukawangi, Literature Synthesis, Indonesia, Management

\section{Introduction}

Coffee is one of Indonesia's leading export commodities. Based on a report released by the International Coffee Organization (ICO), Indonesia is ranked fourth globally as a coffeeproducing country after Brazil, Vietnam, and Columbia (International Coffee Organization, 2018). One of the coffee-producing areas in Indonesia is Sukawangi Village, Sumedang Regency, West Java Province. Coffee is one of the few commodities produced on this plantation. The total production of Sukawangi Village for coffee products in 2017 has reached 200 kilograms $(\mathrm{kg})$. The coffee is produced on farmers' land with an area of approximately 3000 square meters consisting of a mixture of land ownership: privately owned land, Perhutani land, and unused land. The types of coffee grown in Sukawangi Village are Liberica (Coffea Liberica) and Excelsa (Coffea Liberica var. Dewevrei).

Both types of coffee have specific characteristics that can be managed as raw material for various primary and secondary processed products. Even though they can be grown in Indonesia, these two types of coffee do not come from Indonesia but the African continent. Liberica coffee (C. Liberica) comes from Liberia's wild, which is found to also grow in other parts of Africa. Liberica coffee was first brought by the Dutch to Indonesia in the 19th century. Initially, Liberica coffee was grown as a substitute for Arabica coffee plants affected by disease outbreak leaves.

With such conducive geographical conditions, ideally, Indonesia can produce an independent and large-scale coffee industry climate that can help improve the community's welfare, especially coffee farmers and entrepreneurs. Unfortunately, the amount of coffee production in Indonesia is not in line with the development of the coffee industry and its processing.

From seeding to ready-to-drink products, from the coffee production process chain, which generally occurs in Indonesia, only limited to seeding to harvesting the coffee cherries. More than half of Indonesia's coffee exports are raw coffee, especially high-quality coffee such as Arabica. Therefore, it is understandable that foreign companies dominate the coffee beverage market. Most domestic companies are only involved in the instant coffee market, where coffee is processed as coffee beans of relatively low quality.

When viewed from the point of view of added value, the added value of raw materials in the form of coffee to ready-to-consume coffee drinks is enormous. For example, the price of the best raw coffee is usually around IDR 4,000 / kilogram. In contrast, when a coffee drink is in a well-known cafe, the price goes up to IDR 50,000 per glass (about 50 grams). The potential benefits obtained from the coffee industry from increasing the added value of coffee are also more attractive because the technology required to process coffee into ready-to-drink coffee is relatively cheap and straightforward. 
Volume 4 Issue 14 (June 2021) PP. 01-12

DOI: 10.35631/IJEMP.414001

There are two types of coffee production processes that are commonly recognized: wet process and dry process. Wet processing is carried out for high-quality Arabica coffee. In contrast, dry processing is carried out for low-quality coffees such as Robusta, Liberica, and others. The difference in the process is in the washing and fermentation process. These two stages are essential stages that can produce a distinctive coffee aroma. Although the coffee-making process is common, coffee producers in Indonesia are still less interested in managing their crops further.

There has been much involvement from the government and research, and educational institutions to increase the quantity of coffee production with better quality. However, the type of assistance in the form of efforts to increase the added value of domestic coffee with quality coffee production processes is still not significant. Management intervention in the coffee processing industry is one of the main things needed to increase the added value of coffee to increase national income.

\section{Problem Statement}

As the sole actor in running a business, the business actor never calculates the production costs that arise into the cost element. The energy spent by the family is not included in the series of production processes. This fact is one factor that makes the prices of MSME products very affordable to the market without reducing the quality of the products produced.

Microbusiness actors' ability to make efficiency in the production, distribution, and marketing processes makes the products produced can compete. For small business actors running efficiently is a culture that has become a habit in running a business. MSME actors realize that their capacity and financial capacity are limited in running a business, so they will do all the processes that their families can carry out independently. Meanwhile, large industries, with their production capacity and resources, need to build efficiency into a corporate culture.

One of the problems of SMEs is the lack of knowledge of SME entrepreneurs about good business management. Many SMEs only focus on producing goods without thinking about how their business expansion strategy is bigger. As a result, SME entrepreneurs find it difficult to increase their business level. The business they run is not growing, and the turnover they get does not increase.

The next problem faced by SME entrepreneurs is increasing their business competitiveness. An SME entrepreneur also often experiences obstacles in making product innovations. Currently, the number of SME products that can penetrate the international market is still very few. One of the reasons for SME products' difficulty to compete in foreign markets is the low product competitiveness. Moreover, suppose it is related to the price offered. In that case, Indonesian SME products are still far from the quality offered by foreign products.

Other problems of SMEs that often escapes the attention of UKM entrepreneurs is branding. Not many SMEs are aware of the importance of branding for their products and business. So, most SMEs only focus on selling, selling, and selling, without thinking about their products' brand quality. Maintaining the quality of branding is very important in the effort to grow the SME business. With good quality branding, a product will be easier for the audience to remember. The opportunity for sales is even greater. 
Volume 4 Issue 14 (June 2021) PP. 01-12

DOI: 10.35631/IJEMP.414001

The mistake that many UKM players make is that many are not aware that manual bookkeeping is a serious problem for SMEs. Manual bookkeeping is prone to loss, damage, and even recap errors. Thus, entrepreneurs cannot analyze their sales results accurately. For example: if the sales report on a certain day suddenly disappears, the whole sales report will be messy. Good bookkeeping is the key to adequate business evaluation.

With good bookkeeping, SMEs can analyze business sales more precisely as a consideration for making further decisions. Good bookkeeping is also a mandatory requirement for all entrepreneurs who wish to borrow business capital from banks.

\section{Literature Review}

\section{Finance System in The Coffee Industry}

In starting an SME business, it is certain always to pay attention to its finances. The financial sector in every UKM, whether it has been established until now, has not become one of the most crucial and challenging sectors. SMEs across sectors still face lots of challenges and barriers that prevent them from further expanding their companies. Low access to borrowing and limited capital investment, low access to the resources required, low level of experience and raw materials, low management expertise and technical competence were factors involved. According to Harun et al. (2010), the essential financial information that SMEs mainly need to increase their competitiveness or success can be classified into four groups: (i) taxation, (ii) financial accounting, (iii) accounting management and (iv) strategic planning. These services vary between the "rapid growth process" and the "global enterprises. However, to get a better view of their financial status, small and medium-sized businesses require aid in accounting services to enable them to achieve greater financial power. Moreover, SMEs require assistance in using financial instruments such as break-even point, budgeting, financial ratios, and costing analysis. Most of them come from non-financial backgrounds and lack accounting knowledge.

The environmental, financial system is also starting to be implemented in coffee shops and coffee production. Environmental accounting was carried out from 1997 to 2006, which made it possible to assess the environmental and economic tools used in the scheme for over ten years. In all life cycles, the fundamental function of energy has contributed to the growth of various ideas, conjectures, and theories on the relationships between thermodynamics and ecological processes. In assessing the energy flows agricultural driving processes, emerging accounting is commonly practised (Lagerberg and Brown, 1999; Qin et al., 2000; Guarnetti et al.) The environmental contribution to tradable goods and its position in fair trade have been analyzed using energy indices. The country of Nicaragua, for example, depletes its local natural capital by selling green coffee even faster than it imports the revenue it gets for it (Cuadra and Rydberg, 2006). Because it always comes back to consumer behaviour towards brand loyalty. Perhaps what is happening in Nicaragua is that a brand that is a distributor of coffee in Nicaragua has a very loyal consumer.

\section{Consumer Behaviour and Brand Loyalty}

The phenomenon that often appears today is consumer behaviour about coffee, which is trending in various parts of the world. Coffee is not just a commodity, but it is bigger and more meaningful than coffee itself. It has become a habit for many people. Therefore, this study divide it into several aspects, such as: 


\section{Community}

In urban life, coffee shops have been described as 'third places' separate from work and home, offering places for individuals to meet, relax and establish connections. The growing prevalence of coffee shops in the urban landscape, however, has ensured that they are gradually assuming a broader variety of functions, becoming spaces for both recreation and work, while also having social spaces in which people can be able to socialize, in which people can initiate connections, and potentially communities. By recognizing the different ways in which these spaces are co-created by corporations and customers, it could be possible to increase their potential as a space of community.

\section{Drivers of Brand Loyalty}

In general, cognitive drivers (i.e., brand perception, perceived consistency, brand appearance, and perceived value) played an important role in activating happiness and excitement. Meanwhile, affective variables (i.e., pleasure and arousal) serve as important drivers of brand fulfilment, partnership commitment, and brand loyalty. The present study showed that brand recognition, perceived consistency, brand appearance, and perceived value were closely correlated with pleasure; the main drivers of arousal were brand awareness and perceived value. Brand recognition and perceived worth are highly significant in that these factors are the primary causes of satisfaction and enjoyment and the main indirect contributors to the generation of brand loyalty. With these major outcomes, chain coffee shop practitioners should consider making multiple attempts to boost the brand recognition and subjective worth of patrons to maximize the level of affective/emotional interactions of consumers at a coffee shop and brand loyalty.

\section{Loyalty}

Before buying a coffee drink, there are six indicators that customers must remember. Taste, product style, environment, brand impact, accessibility to the venue, and price are the main influences. Survey-based research showed that intake is influenced by only three variables: flavour (ingredients and how they are made), product style (product packaging, colours, materials, textures, coffee forms, and arrangement), and ambience. The "ambience" is rated as the best; ambience directly relates to the physical environment and consumer loyalty in deciding which factor is most significant. It is understood that the correct atmosphere would guarantee that consumers replicate their purchases in the future. Moreover, if the coffee shop has a positive appearance, they can pay more for the stuff. The most critical factor is closely accompanied by "taste" after ambience, with the least important one being "design".

\section{Green Practices}

Green practices have been a major indicator of the emotional commitment of customers to a shop. Furthermore, consumers' retail connection has been shown to have a beneficial impact on loyalty to a green shop, which is closely related to loyalty to a green good. Further analysis of the moderating influence of green awareness found that the green consciousness of customers greatly changed the way their views of green activities converted into resulting relational attachment as well as loyalty to a shop. Compared to the low green-consciousness community, the views of shops' green practices by high green-consciousness customers had greater effects on their store attachments, leading to greater loyalty to green products. In the SME coffee business, it would be wise to diversify its cultivation to create extraordinary results that can be brewed and served to loyal customers. 


\section{Diversification Farming}

One way to diversify its cultivation currently being discussed by many people is by doing diversification farming. Diversification is developing an increasingly diverse portfolio of activities and assets for rural communities to survive and thrive in their living conditions. Diversification activities may relate to a variety of on-farm, off-farm, and non-farm activities that individuals or households participate in to generate cash income, provide food for household consumption, or achieve other personal benefits contentment.

A study conducted by Scoones and Ellis showed the adapted sustainable livelihoods framework. It described several aspects of coffee farmers. The first aspect is vulnerability, divided into stressors (e.g., weather, and seasonal food insecurity) and shocks (e.g., coffee pests and disease, coffee price drops). Coffee farmers usually have three sources of assets: natural assets (e.g., land ownership, agrobiodiversity), financial assets (on-farm, off-farm benefits, volume of coffee production), human assets (household size composition). Coffee farmers do not just plant coffee on their land, but some also plant maize and beekeeping.

Farmers' households handle several activities on their farms. In addition to coffee, almost all households (98.2 percent) had fruit trees, and 87.4 percent of respondents reported raising poultry. Maize is also widely used to feed farm animals and poultry, so its production can benefit poultry or farm animal raising. Aquaculture and livestock were the least popular activities among the activities listed in the survey.

Households of coffee farmers have received cash income from different sources. Farmers registered an average of 3.4 sources of income in addition to coffee. As noted elsewhere, government subsidies are a significant income source for smallholder farmers ( $\mathrm{Ja}$ ee, 2014; Robles Berlanga, 2011). Cash transfers/agricultural subsidies (81.1 percent), PES systems (46.2 percent), purchases of cattle or food goods (35.6 percent), on-farm agricultural labour (29.6 percent) and small enterprises were the most widely recorded sources of income (21.9 percent). Farmers mixing beekeeping with the output of staple crops (G4) were more likely to consider their income as 'sufficient'. In contrast, the G2 farmers displayed the lowest chance, although this was not statistically important. The findings show that the chance rises for both classes as the sum of income sources on the farm increases.

Another study shows that coffee farmers also plant cocoa besides coffee. When areas are vulnerable to coffee, cocoa may theoretically become an option. Agroforestry of tree species currently favoured is particularly vulnerable to potential climate change. The best approach to adjusting much of the coffee and cocoa production areas could be to transform agroforestry processes by modifying tree species' composition. The findings illustrate the importance of preparing for land use, considering the impact of climate change, and evaluating new combinations of agroforestry species in Mesoamerican coffee and cocoa plantations since coffee is more vulnerable than cocoa to climate change. Besides the importance of land use preparation, it is also important for an SME business to open and run its business by having regulations or even a certificate.

\section{Regulation/ Certification}

The number of SME coffee businesses that have sprung up makes this coffee business very easy to find anywhere. Therefore, regulations have been enacted, which hopefully can regulate the emerging coffee business. Certification systems and sustainable cooperative requirements are now a common feature in many agricultural ecosystems around the world. Improved 
Volume 4 Issue 14 (June 2021) PP. 01-12

DOI: 10.35631/IJEMP.414001

subsistence properties derived from certification under complex structural and conceptual conditions have become difficult to determine causation. A larger percentage of studies have observed neutral or mixed impacts, and a limited number have documented adverse effects. Another study also showed that the prevalence of sustainability codes, rating systems and labelling statements in the sector has contributed to market worries about the environmental and social conditions of coffee production. Global private control drives systemic shifts in farm organization modes, trader-farmer partnerships. It contributes to expanded upstream penetration of international trading Businesses in coffee-producing regions across Indonesia. Rising transaction costs along the supply chain and exerting a general downward pressure on farmgate prices could be an unintended result of these changes in the future. However, what a business that is well regulated and certified but does not care about the environment. Therefore, few coffees shops care about the environment and have even made sustainability one of their campaigns.

\section{Sustainability Environment}

Apart from regulation, the market approach is also a very important consideration in engaging a new market. The market approach to sustainability in coffee consolidates vigorous free guidelines and certification frameworks, person company plans, and industry-wide activities. Speculations by the industry incorporate paying premiums to compensate ranchers for their supportability homes, giving preparing and specialized help to ranchers to empower this application, and steadily supporting forms outside the cultivation within the more extensive community to relieve systemic social and natural problems.

As companies increment their speculations in maintainability through sourcing approaches and specialized programs, there ought to be a solid part for gracious society organizations that bring mastery in organic and social sciences and specialized capacity and built-up community relations coffee creating nations. Governments still play a basic part in advancing social incorporation, moving forward framework, and encouraging producers' get to administrations.

Guidelines and certification frameworks bring a codified approach to directing, confirming, and communicating supportability. With the solid level of belief, they have built with customers, they serve as unparalleled advertisement components to change over those shoppers' desires into positive come about on coffee farms.

Empirical proof that serves as the premise for directing the proceeded advancement of maintainability is very constrained. A need to prove could be a chance for future ventures, which may not be guided by learning. A hazard to the validity of strong frameworks, since less requesting or straightforward approaches, may be displayed as maintainable, suggesting that they convey similarly solid results. The improvement of a supportability system through the collaboration of the Worldwide Coffee Stage and Feasible Coffee Challenge will present more consistency in information collection and investigation and decrease the issue of the to a great extent isolated assessment endeavours developing from the research. However, the things that have been mentioned above are, of course, arranged by considering the value chain of coffee itself. Therefore, in discussing coffee, we will not go too far about the product value chain.

\section{Product Value Chain}

The long chain of the coffee industry, including the market approach and the sustainability part, is very likely to create discrepancies the misalignment of lead firm needs and the territorial teach supporting Topographical Signs within the Indonesian coffee division has come about in 
disappointment to capture the place-related esteem inserted inside strength coffee items effectively. Whereas a few Indonesia-based on-screen characters (such as trading firms) have ended up viably implanted with the rationale of the coffee GPN, the overwhelming regulation situations in both case-study locales stay solidly dug in in-state relations and a state-based rationale of (extractive) aggregation and typical activity. The foundation of GIs, and the tall level of state intrigued in them, can be clarified not by a veritable commitment to esteem creation and capture with the GPN, but a commitment to a domestically oriented political economy and ceremonial support of connections between the state and country populaces. Whereas the GPN concepts of key coupling and esteem capture directions have given a valuable conceptual focal point through which to dissect forms that might lead to esteem capture and provincial improvement, this ponder has assisted this plan by considering territorial improvement results item of localized, path-dependent socio-institutional advancement.

This research supports an agreement with Bowen (2010) proposal of 'institutional monocropping' of GIs, where the technocratic application of a GI framework borrowed from Europe has fizzled to create any substantial benefits for makers inside the organization milieu of Indonesia. Be that as it may, our discoveries propose an encouraging, maybe unforeseen, set of social forms where the assignment of GI regulation shapes is serving an unmistakable set of political and social destinations inside Indonesia. Our evaluation of the political setting inside which territorial teach around the GIs have risen in Indonesia proposes that giving advanced specialized back and assets for organization reinforcing of the MPIGs is impossible to cure the regulation disappointment. A key knowledge from this ponder has been how the GIs themselves have been re-shaped by nearby regulation settings to serve political targets very particular from their eagerness somewhere else.

It is vital to perceive that the primary three drivers of state interest in GIs distinguished within the past area, which in turn shape the territorial regulation environment inside which the GIs are inserted, are all fulfilled at the point when the GI is formally enlisted (arrange one within the ToC). The GI does not really ought to be appropriately working, packed with complicated quality control instruments, to figure out these results. The fourth driver, in differentiate, requires a dynamic engagement with ethical and moral wrangles about destinations of utilization. As often as possible, GIs' intangible benefits raised by a few performing artists in Indonesia appears somewhat to insinuate this non-technical ethical claim over mental property. For this goal to be effective, be that as it may, creating nation interface ought to not as it were be aligned with quality traditions along the esteem chain, they have to be politically lock in with the ethical authenticity of roasters and café proprietors to utilize put names and social property without recognizing maker claims of proprietorship. (In this setting, it is critical to perceive that promotion associations within the US, such as Oxfam, played a basic part in constraining the forte simmering division to, in the long run, sign permitting understandings over the Ethiopian trademarks.) Such an ethical claim would request that the typical esteem and quality traits in speciality coffee items are more evenly shared between creating and expanding nation performing artists, which might lead to more veritable associations within the segment. It would, in any case, require the dynamic development of modern ethical and quality traditions to permit forms of esteem capture and GPN updating. Behind the coffee industry, which is very advanced nowadays and is popular to buy in Indonesia, this industry is still affected by something that is happening, such as COVID-19. 


\section{COVID-19 Impact}

The International Monetary Fund (IMF) has cautioned that COVID-19 seems to result in one of the most exceedingly bad financial fallouts. Amid figures of a worldwide financial downturn, the money-related impacts of this novel illness will likely be long-lived and exact uneven impacts over product markets and people. The dangers of COVID-19 posture to the worldwide coffee segment are overwhelming, with significant suggestions for makers.

Earlier to COVID-19, coffee pioneers had been concerned that small-scale generation was drawing nearer to a tipping point as costs had fallen to generally moo levels (Sieff, 2019). COVID-19 may, in this way, thrust the division into social and financial change, with smallholders among the hardest hit. The impacts on the smallholder framework are established within the systemic powerlessness of the coffee generation framework and the unequal ways it is organized: huge incomes from the sale of coffee within the Worldwide North are made conceivable by, for the most part, devastated smallholders within the Worldwide South.

\section{Coffee Producers Vulnerabilities}

Coffee is central to the financial, social, and social texture of numerous nations. In any case, coffee's generation framework destabilizes the vocations of smallholders. Farmgate costs vacillate concurring to universal markets, and supply is overwhelmed by some creating nations (ICO, 2019a). Coffee, too, makes trade reliance for its makers as it were $30 \%$ of all coffee sold inside creating nations (ICO, 2019a). In unfavourable times agriculturists have trouble exchanging to other crops since coffee trees require huge and long-term speculations (Eakin et al., 2011, ICO, 2019a). Additionally, generation costs have consistently expanded for a long time (ICO, 2019a), while regulation back for smallholders has melted away. In specific, national speculations in rural advancement have remained or declined.

\section{Production Costs Outpacing Coffee Revenues}

Smallholder incomes depend on the amounts sold and the farmgate costs, both of which change considerably by season and developing area. At the same time, generation is affected by the utilization of fertilizers, pesticides, and water systems and the climate and rates of plant bothers and maladies, farmgate cost changes by assortment, quality, and advertising goals. The wide extent of farmgate costs is clear in Fig. 2. Smallholder benefits moreover depend on working costs which regularly outpace swelling. Between 2016 and 2018, fertilizer costs expanded globally by more than $25 \%$ (ICO, 2019b). 


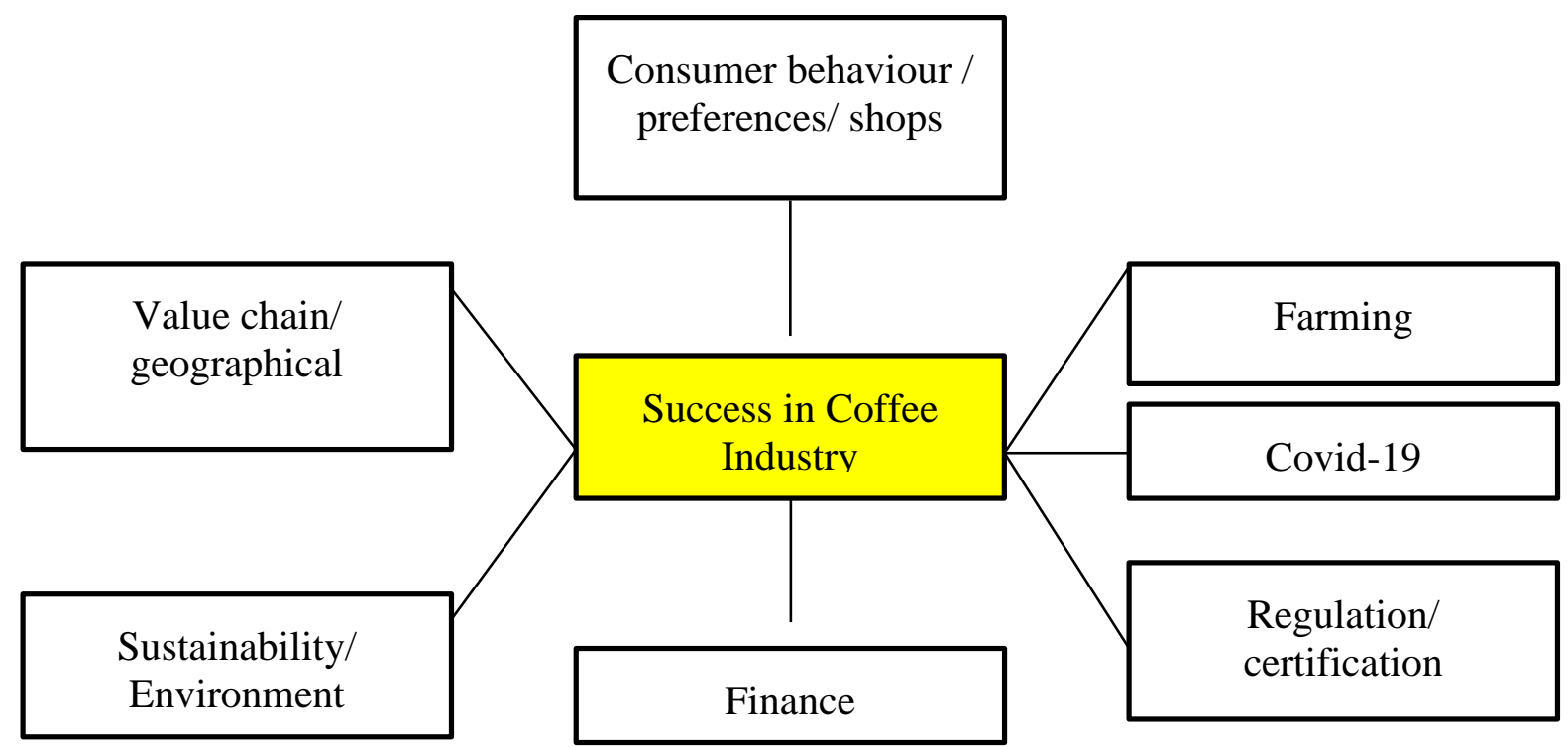

Figure 1: Conceptual Model Based on Literature Review Analysis

Source: Author's Analysis

Based on the analysis of literature review, it can be concluded that there are several factors that can influence the success in coffee industry. The coffee industry can be divided into two main classifications, the upstream and downstream business. The upstream part consists of the process from harvesting the coffee as a raw material into intermediate goods. This process includes farming method, regulation and certification, the environment or sustainability, and adaptation during covid 19. The downstream part includes delivering the intermediate goods to the final customer, consisting of the coffee shops determinants, which are the consumer behaviour and preferences.

To become successful in the coffee industry, these factors are required. Covid 19 is one of the factors being considered because of the coffee farmer's vulnerability to the market's condition, in which coffee trees require huge and long-term speculation. People do not want to do speculation during crises such as covid 19 due to the high uncertainty. Another factor considered is coffee's value chain. The improvement of the relationship among the stakeholders is required to prevent key individuals within the producer community to accumulate wealth and social position, contributing to inequality rather than poverty alleviation efforts. Next, the Farming technique that coffee farmers should consider is Diversification farming. Farmer's plant other plants besides coffee in on-farm activities. As for sustainability and the environment, the concern is increasing. The market approach to sustainability in coffee consolidates vigorous free guidelines and certification frameworks, personal company plans, and industry-wide activities. Also, the regulation and certification within the coffee business is extensive. Certification systems and sustainable cooperative requirements are now a common feature in many agricultural ecosystems around the world.

A larger percentage of studies have observed neutral or mixed impacts, and a limited number have documented adverse effects. Another factor vital in a downstream coffee business is consumer behaviour and loyalty associated with the coffee shop. The drivers of brand loyalty 
are the cognitive drivers (i.e. brand perception, perceived consistency, brand appearance, and perceived value), which played an important role in activating happiness and excitement. Meanwhile, affective variables (i.e., pleasure and arousal) serves as a vital brand fulfilment. Other loyalty drivers are taste, product style, environment, brand impact, accessibility to the venue, and price. Green practices have also been a major indicator of the emotional commitment of customers to a shop. Furthermore, consumers' retail connection has been shown to have a beneficial impact on loyalty to a green shop. Another literature also states that coffee shop is arguably will grow to become a community space in the future.

\section{References}

Anderzén, J., Guzmán Luna, A., Luna-González, D. V., Merrill, S. C., Caswell, M., Méndez, V. E., Hernández Jonapá, R., \& Mier y Terán Giménez Cacho, M. (2020). Effects of on-farm diversification strategies on smallholder coffee farmer food security and income sufficiency in Chiapas, Mexico. Journal of Rural Studies, 77(February), 33-46.

Apriani, E., Kim, Y. S., Fisher, L. A., \& Baral, H. (2020). Non-state certification of smallholders for sustainable palm oil in Sumatra, Indonesia. Land Use Policy, 99, 105112.

Ferreira, J., Ferreira, C., \& Bos, E. (2021). Spaces of consumption, connection, and community: Exploring the role of the coffee shop in urban lives. Geoforum, 119(January), 21-29.

Giannetti, B. F., Ogura, Y., Bonilla, S. H., \& Almeida, C. M. V. B. (2011). Accounting emergy flows to determine the best production model of a coffee plantation. Energy Policy, 39(11), 7399-7407.

Guido, Z., Knudson, C., Finan, T., Madajewicz, M., \& Rhiney, K. (2020). Shocks and cherries: The production of vulnerability among smallholder coffee farmers in Jamaica. World Development, 132, 104979.

Guido, Z., Knudson, C., \& Rhiney, K. (2020). Will COVID-19 be one shock too many for smallholder coffee livelihoods? World Development, 136, 105172.

Han, H., Nguyen, H. N., Song, H., Chua, B. L., Lee, S., \& Kim, W. (2018). Drivers of brand loyalty in the chain coffee shop industry. International Journal of Hospitality Management, 72(November 2017), 86-97.

Husin, M. A., \& Ibrahim, M. D. (2014). The Role of Accounting Services and Impact on Small Medium Enterprises (SMEs) Performance in Manufacturing Sector from East Coast Region of Malaysia: A Conceptual Paper. Procedia - Social and Behavioral Sciences, 115(Iicies 2013), 54-67.

Jang, Y. J., Kim, W. G., \& Lee, H. Y. (2015). Coffee shop consumers' emotional attachment and loyalty to green stores: The moderating role of green consciousness. International Journal of Hospitality Management, 44, 146-156.

Millard, E. (2017). Still brewing: Fostering sustainable coffee production. World Development Perspectives, 7-8(November), 32-42.

Neilson, J. (2008). Global Private Regulation and Value-Chain Restructuring in Indonesian Smallholder Coffee Systems. World Development, 36(9), 1607-1622.

Piao, R. S., Fonseca, L., Carvalho, E., Macchione Saes, M. S., \& Florencio de Almeida, L. (2019). The adoption of Voluntary Sustainability Standards (VSS) and value chain upgrading in the Brazilian coffee production context. Journal of Rural Studies, 71(August), 13-22.

van Keulen, M., \& Kirchherr, J. (2021). The implementation of the Circular Economy: Barriers and enablers in the coffee value chain. Journal of Cleaner Production, 281, 125033. 
Volume 4 Issue 14 (June 2021) PP. 01-12 DOI: 10.35631/IJEMP.414001

Vicol, M., Neilson, J., Hartatri, D. F. S., \& Cooper, P. (2018). Upgrading for whom? Relationship coffee, value chain interventions and rural development in Indonesia. World Development, 110, 26-37.

Von Geibler, J., Cordaro, F., Kennedy, K., Lettenmeier, M., \& Roche, B. (2016). Integrating resource efficiency in business strategies: A mixed-method approach for environmental life cycle assessment in the single-serve coffee value chain. Journal of Cleaner Production, 115(2016), 62-74. 